\title{
Negotiating tensions, creating connections: The NZGS early career research network
}

\author{
Sandy Lee $^{1}$ | Brendon Blue ${ }^{1}$ (1) | Gail Adams-Hutcheson ${ }^{2}$ | Pascarn Dickinson ${ }^{3}$
}

${ }^{1}$ School of Environment, University of Auckland, Auckland, New Zealand

${ }^{2}$ School of Social Sciences, University of Waikato, Hamilton, New Zealand

${ }^{3}$ School of Geography, Environment and Earth Sciences, Victoria University Wellington, Wellington, New Zealand

\section{Correspondence}

Brendon Blue, School of Environment, The University of Auckland, Private Bag 92019, Auckland 1142, New Zealand. Email: b.blue@auckland.ac.nz

\begin{abstract}
The New Zealand Geography Society Early Career Research Network (NZGS ECRN) is a peer-run network aiming to foster a welcoming and supportive environment for those who identify as early career geographers in Aotearoa New Zealand. This article highlights how the ECRN is working to find space for intervention and connection in an international context of precarity for early career researchers, as well as addressing the ongoing challenges of effectively representing the interests of a diverse and transient group of scholars.
\end{abstract}

\section{K E Y W O R D S}

tertiary education, precarity, New Zealand geography, peer support, student wellbeing

\section{1 | INTRODUCTION}

Early career geographers in Aotearoa New Zealand face a challenging combination of possibility and precarity as we work towards completing our studies and begin to establish our identities as researchers or researchinformed professionals. The traditional postdoctoral trajectory of an overseas fellowship, hopefully followed by a secure academic post, may make sense for some but involves levels of financial risk and relational upheaval which are untenable for many. For those whose circumstances do not facilitate such international mobility, completing a higher research degree can mean entering an uncertain and isolating world of fixed-term contracts, competitive funding and unpaid self-promotional labour.

Many postgraduates do not even make it that far, as concern mounts internationally regarding student mental health. Growing evidence suggests that in Western nations, across a wide range of subject areas, students are

Note regarding authors: this paper was written on behalf of the NZGS ECRN by a group of early career researchers named here in no particular order: Sandy Lee and Brendon Blue (School of Environment, University of Auckland), Gail Adams-Hutcheson (School of Social Sciences, University of Waikato) and Pascarn Dickinson (School of Geography, Environment and Earth Sciences, Victoria University of Wellington). substantially more likely than the general population to report various forms of stress and distress (Evans, Bira, Gastelum, Weiss, \& Vanderford, 2018). As well as broader societal pressures facing young people such as increasing costs of living, workforce casualization and student debt, all of which weigh heaviest on those facing other structural disadvantage, geographers have specifically implicated academic environments, with individualistic cultures and apparently indifferent institutional governance provoking anxiety, insecurity and isolation among both students and staff (Berg, Hijbens, Edward, \& Larsen, 2016; Hawkins, Manzi, \& Ojeda, 2014; Peake \& Mullings, 2016).

These circumstances are conditioned by shifts in the perceived nature and purpose of university education. As in many other developed nations, New Zealand universities were once regarded as providers of education as a fundamental public good; if one that primarily benefitted a relatively small set of students who achieved university entrance from secondary school. Since the 1980s, however, these institutions have undergone a series of shifts towards becoming transnational businesses competing in a global knowledge economy (Collins \& Lewis, 2016; Shore, 2010). Required to be increasingly self-sustaining, while struggling to retain their positions in world rankings, New Zealand universities focus on competing for 
student enrolments and performance-based research funding while cutting costs through restructuring and auditing staff performance.

Meanwhile the global market for higher education is producing doctoral graduate numbers at a rate significantly out of step with permanent academic jobs, producing an international discourse of crisis regarding the $\mathrm{PhD}$ (Cuthbert \& Molla, 2015). Consistent with an understanding of university education as an individual financial investment valued primarily for its rate of return (e.g., O'Callaghan, 2013), New Zealand universities and government have responded by focusing on producing "industryready" graduates who are more employable and complete their studies more quickly (Cuthbert \& Molla, 2015). Graduate students in New Zealand are under increasing pressure as a result, with extensions restricted, scholarship durations limited and, since 2013, eligibility for student allowances rescinded.

After hurrying through their degrees, many New Zealand postgraduates join the growing ranks of junior researchers on short-term and part-time teaching and research contracts, wondering how long to persist spending unpaid time writing high-stakes grant applications and carrying out self-promotional labour in the hope of securing an academic role. For members of traditionally underrepresented groups in academia, who may not have the privilege of family safety nets to fall back on, these decisions can be particularly consequential. Even these short-term roles, which provide important stepping-stones into academic careers, are increasingly difficult to come by for two reasons. First, the net loss of 70 government-funded Foundation for Research, Science \& Technology post-doctoral fellowships in 2010 when funding was reallocated towards a small number of awards targeting elite researchers who are further into their careers. Second, New Zealand universities require substantial overhead payments on most externally funded postdoctoral fellowships, more than doubling the salary cost of including postdoctoral fellowships in grant applications (Griffin, 2012; Nicholls, 2017). A growing sense that an academic career is only for a lucky few accompanies uncertainty regarding alternative options (DuftyJones, 2018), as well as a sense that once individuals "bail out" of an academic career path there is little prospect of ever going back.

It is within this challenging context that the New Zealand Geographical Society Early Career Research Network (NZGS ECRN) orientates its practice. In this brief article we describe how we, as a group of postgraduate and early career geographers representing the NZGS ECRN, are responding to these circumstances and finding productive ways of supporting early career researchers' (ECRs) intellectual and professional development. The article begins with a brief overview of what the ECRN is, and its purpose within the Network's particular sphere of influence. We then describe an intervention we organised for the 2018 NZGS-IAG Conference, informed by an awareness of the challenges discussed above. Finally, we reflect on the future of an NZGS ECRN which relies heavily on volunteer labour from a dispersed, transient population of researchers.

\section{2 | THE EARLY CAREER RESEARCH NETWORK}

The NZGS ECRN is a national network of postgraduate students, teaching fellows, researchers and others who identify as early career geographers. It is funded and supported by the NZGS as part of its programme to enhance the experience, skills and sense of community among postgraduate and early career geographers. The ECRN started life as the New Zealand Geographical Society Postgraduate Network, formed by representatives from across New Zealand's universities after a workshop at the combined NZGS/IGU Christchurch conference in 2010. The Network was subsequently renamed and expanded in 2017 to acknowledge and include members who had completed their studies and moved on to academic roles, Crown Research Institutes or other endeavours. This expansion saw the Network turn some of its attention towards supporting its members as they undergo these transitions.

As representatives of the ECRN, we recognise that we have limited control over the structural conditions in which ECRs develop their careers. We also, however, see substantial potential for a national network to offer solidarity, support and a means of communicating across a broad set of emerging geographers. Influenced by geographical thinking about intellectual and institutional capability and practices of engaged scholarship (see Le Heron, Le Heron, \& Lewis, 2011), the Network seeks to build capability in the New Zealand geography community by providing opportunities for ECRs to establish supportive relationships, up-skill and "up-relate" through meetings, seminars and conference events (see NZGS-PG Network, 2014 for a discussion on "up-relating"). The ECRN also has a vibrant social media presence, advertising academic seminars, university vacancies and funding possibilities for those who may have lost institutional access but wish to remain involved in academic life. These activities are facilitated on a voluntary basis by a gradually evolving set of representatives, most of whom are themselves in precarious or part-time positions.

The ECRN's relationship with the NZGS has several benefits for both ECRs and the discipline of geography in 
New Zealand. Two national co-representatives represent the ECRN on committee, council and AGM meetings, providing an opportunity for the Network to speak on behalf of early career geographers to raise concerns and issues to the national Executive Committee. These roles, along with a third co-opted ECR position which has been included on the NZGS executive committee since 2016, provide important opportunities for representatives to foster connections with senior academics outside supervisory relationships beyond their own institutions. These informal mentorships can be an especially important part of academic life (Adams-Hutcheson \& Johnston, 2019).

Representation on the Executive Committee also provides an opportunity for ECRs to be part of the development of geography in New Zealand at both tertiary and secondary levels. At a time when academic and school geography are perceived to have drifted apart internationally (e.g., Stannard, 2003), early career geographers can provide an important connecting voice: not only does their research often place them at the leading-edge of contemporary geographic debates, but many are also closely engaged with the experiences of undergraduate students through teaching assistantships or contract lecturing roles.

\section{3 | CREATING CONNECTIONS}

For a national-scale network comprising a transient population of ECRs, a biennial national conference provides a vital opportunity for recruitment, connection and intervention. The combined NZGS-IAG conference, Creative Conversations, Constructive Connections, held in Auckland 11-14 July 2018 provided a natural focal point for the ECRN's activities in 2018. The Network therefore convened a pre-conference workshop for postgraduate students and early career researchers, comprising an afternoon of panel discussions followed by an evening reception open to postgraduates, other ECRs and keynote speakers attending the conference. Hosted by Sandy Lee and Brendon Blue, the ECRN's University of Auckland representatives, the day was extremely well attended by postgraduates and ECRs from both New Zealand and Australia.

Panel discussions centred around two key themes, both addressing what the NZGS understood to be some of the main challenges facing postgraduate students and ECRs. The first panel, moderated by Swati Shah and Gail Adams-Hutcheson, focused on academic publishing. The panel responded to increasing pressure on postgraduate students to emerge from their degrees with publications either already completed or underway, particularly if they seek an academic career. The ECRN invited four panellists representing key local and international geography journals to present brief reflections on the key improvements authors can make to their articles before submitting to their journal, the most common reasons for rejecting manuscripts, and one lesson about publishing that they wish they had been told early in their career. This was followed by a lively question and answer session.

The second session, moderated by Nick Kirk and Sarah Edwards, aimed to provide attendees with a broadened sense of the potential career pathways open to them after their degrees. With panellists representing a range of career options and different career stages both inside and outside the academy, it addressed the reality that academic careers may be neither feasible nor necessarily desirable for a substantial proportion of $\mathrm{PhD}$ graduates. The four panellists reflected on their own career trajectories post- $\mathrm{PhD}$, as well as the challenges and opportunities that influenced their career choices. Panellists drew attention to a diverse set of career options, particularly highlighting possibilities for impactful research and translation work in Crown Research Institutes as well as local and central government. They spoke of the value of mentors in helping early career researchers identify the skills they have developed through their studies, and suggested that graduates think of the various "selves" they can draw on to craft identities highlighting relevant skills when applying for different kinds of roles. They also noted the substantial role of luck in their own career pathways, the importance of not blaming oneself for perceived failures, and the need for graduates to consider how they want to live their lives. The floor was then again opened up to the audience for questions.

The evening reception, generously supported by the NZGS, provided a valuable opportunity for postgraduates and ECRs to connect with each other, with panellists from the afternoon's discussions, and with some of the conference's keynote speakers before the academic programme officially began the following day. Events such as these provide an important sense of community and shared identity, allowing early career researchers to expand their networks and to feel connected with colleagues who they will continue to see throughout the conference. Informal feedback on both the panel sessions and the evening reception was very positive.

\section{4 | ADDRESSING CHALLENGES}

The successful pre-conference event in 2018 reaffirms the importance of a national early career network. Maintaining a vibrant and engaged community at this scale does, however, stretch the capacity of its small group of volunteer 
representatives who are busy completing their studies or developing their own careers. The inherently transient nature of early career researchers, their dispersed physical locations and their wide-ranging research interests present particular challenges to the ECRN's efforts to connect with and provide for the diverse early career geography community in New Zealand.

The early career geography community also undergoes constant turnover as new students arrive and former ECRs move on with their careers. Keeping track of potential members is therefore a continual challenge for the Network, requiring ongoing recruitment and outreach to fulfil the network's aim of building horizontal and vertical support for ECRs. In practice, the work of establishing relationships with new scholars largely falls to individual committee members at particular institutions, creating a strong cohort-effect as they recruit through their personal networks. It can also be difficult to ensure that members stay connected as they move between universities, transition into Crown Research Institutes, local councils and other jobs, or become busy with the demands of teaching and research.

Understanding and representing the broad interests of those who do engage with the network also presents an ongoing challenge. As might be expected of a geographical organisation, membership of the ECRN encompasses researchers studying a wide range of subject matter through a broad array of methodologies: from mainstream and critical human geographers, to physical geographers, to those who fall somewhere in-between. Members also encompass a wide range of career stages, from master's and doctoral students to professional teaching fellows, research fellows and lecturers. They might be unpaid, on precarious short-term contracts, or in more established and permanent roles.

This diversity presents opportunities for crossdisciplinary collaboration and learning, as well as for mentoring and support between cohorts. Meeting the varied needs of these scholars, however, many of whom might see the world in different ways and anticipate rather different career pathways, remains a work in progress. For example, the panels for the 2018 preconference event were largely targeted at the perceived needs of PhD students because they represent the largest target "market." Other postgraduate students reported finding the panels informative and useful, but targeting only a portion of the Network's potential audience neglects the needs and concerns of others, including those who might be considering a PhD in the future.

Addressing these two interrelated challenges requires refreshing and diversifying the group of volunteer representatives to better reflect a wider range of early career geographers. At present, the majority of the network's branch representatives have completed $\mathrm{PhDs}$ and are in research and/or teaching positions in academic institutions. Most, though not all, would identify as human geographers. Involvement from representatives at different career stages and encompassing a broader spectrum of research interests, especially postgraduates who are near the beginning of their studies, would strengthen the ECRN's ability to understand and connect with the diverse set of early career geographers that it seeks to represent. Representatives are more likely to have regular contact with their own cohorts, enabling them to gauge the concerns and interests of their peers and voice them within the network, as well as to promote the network to their peers and encourage membership. It would also inform the development of events and activities that are responsive to the experiences and needs of a wider set of early career geographers in New Zealand. Greater representation from Masters students, for example, might encourage more specifically targeted pre-conference sessions, such as one for those considering doctoral studies. Such a session could comprise current $\mathrm{PhD}$ students sharing their personal experiences of undertaking their degrees, discussing why they chose to embark on one and what it entails as well as providing opportunities for prospective students to ask questions that are of most concern for them.

By providing spaces in which a diverse set of emerging scholars can be geographers, the ECRN plays an important role in strengthening and maintaining the identity of geography as a discipline in New Zealand. It strives to foster a sense of community among scholars who might otherwise feel isolated and disconnected, providing opportunities to develop professional skills, find emotional support and to build national and international networks. The Network also provides a collective voice for ECRs on the national executive committee, enabling the ECRN to communicate some of the challenges that geographers encounter as they navigate the early stages of their careers. We call on the geographical community in New Zealand to contribute to the network by identifying and nominating early career geographers to volunteer as branch representatives. With the 2020 NZGS conference in Wellington fast approaching, we hope for a mix of representatives to help put on a preconference event that meets the needs of a wide range of early career geographers, and which the ECRN can continue to build from into the future.

\section{ACKNOWLEDGEMENTS}

The NZGS ECRN is grateful for the generous participation of all panellists involved in the NZGS-IAG early career pre-conference day, especially those who had to 
change their travel plans to be there. Panellists on the publication panel were Associate Professor Juliana Mansvelt (Managing editor, The New Zealand Geographer), Massey University, New Zealand; Professor Eugene McCann (Managing editor, Environment \& Planning C: Politics \& Space), Simon Fraser University, Canada; Professor Elaine Stratford (Editor-in-Chief, Geographical Research), University of Tasmania, Australia; and Professor Sarah Turner (Editor, Geoforum) McGill University, Canada. Panellists on the careers panel were Dr Tom Baker (University of Auckland, New Zealand), Dr Lucy Baragwanath (Victoria University of Wellington, New Zealand), Alison Greenaway (Manaaki Whenua Landcare Research, New Zealand) and Harvey Perkins (University of Auckland, New Zealand). The NZGS ECRN also thanks Harry Shi for assisting with the panel discussions. The Network gratefully acknowledges the generous and proactive support of the conference organisers, Karen Fisher and Nick Lewis, as well as the sponsorship provided by the NZGS.

\section{ORCID}

\section{Brendon Blue (10) https://orcid.org/0000-0002-4310-4489}

\section{REFERENCES}

Adams-Hutcheson, G., \& Johnston, L. (2019). Flourishing in fragile academic work spaces and learning environments: Feminist geographies of care and mentoring. Gender, Place \& Culture, 26(4), 1-17. https://doi.org/10.1080/0966369X.2019. 1596885

Berg, L., Hijbens, D., Edward, H., \& Larsen, H. (2016). Producing anxiety in the neoliberal university. The Canadian Geographer, 60(2), 168-180.

Collins, F. L., \& Lewis, N. (2016). New Zealand universities: The prospects and pitfalls of globalizing higher education. In The Palgrave handbook of Asia Pacific higher education (pp. 597-613). New York, NY: Palgrave Macmillan.

Cuthbert, D., \& Molla, T. (2015). PhD crisis discourse: A critical approach to the framing of the problem and some Australian 'solutions'. Higher Education, 69(1), 33-53.
Dufty-Jones, R. (2018). The career aspirations and expectations of geography doctoral students: Establishing academic subjectivities within a shifting landscape. Geographical Research, 56(2), 126-138.

Evans, T., Bira, L., Gastelum, J., Weiss, L., \& Vanderford, N. (2018). Evidence for a mental health crisis in graduate education. Nature Biotechnology, 36(3), 282-284.

Griffin, P. (2012) Do emerging researchers have a future in NZ? [Sciblogs]. Retrieved from https://sciblogs.co.nz/griffins-gadgets/ 2012/04/17/do-emerging-researchers-have-a-future-in-nz/.

Hawkins, R., Manzi, M., \& Ojeda, D. (2014). Lives in the making: Power, academia and the everyday. ACME: An International EJournal for Critical Geographies, 13(2), 328-351.

Le Heron, E., Le Heron, R., \& Lewis, N. (2011). Performing research capability building in New Zealand's social sciences: Capacitycapability insights from exploring the work of BRCSS's 'sustainability' theme, 2004-09. Environment and Planning A: Economy and Space, 43(6), 1400-1420.

Nicholls, J. (2017) 'Where have all the postdocs gone? The blockage in our science 'talent pipe'. Retrieved from https://www.noted.co. $\mathrm{nz} /$ currently/currently-science/where-have-all-the-postdocsgone-the-blockage-in-our-science-talent-pipe.

NZGS-PG Network. (2014). Postgraduates performing powerfully in a changing academic environment. New Zealand Geographer, 70(1), 61-68

O'Callaghan, D. (2013) Degrees ranked by earning potential. Retrieved from http://www.stuff.co.nz/national/8205505/ Degrees-ranked-by-earning-potential.

Peake, L., \& Mullings, B. (2016). Critical reflections on mental and emotional distress in the academy. ACME: An International EJournal for Critical Geographies, 15(2), 253-284.

Shore, C. (2010). Beyond the multiversity: Neoliberalism and the rise of the schizophrenic university. Social Anthropology, 18(1), 15-29.

Stannard, K. (2003). Earth to academia: On the need to reconnect university and school geography. Area, 35(3), 316-332.

How to cite this article: Lee $S$, Blue B, AdamsHutcheson G, Dickinson P. Negotiating tensions, creating connections: The NZGS early career research network. N Z Geog. 2019;1-5. https://doi. org/10.1111/nzg.12245 